\title{
EVIDENCE BASED LEARNING: AN ANALYSIS OF IMPACT OF REMEDIAL TEACHING ON CONCEPTUAL UNDERSTANDING
}

\author{
Prashant Thote ${ }^{*}{ }^{凶}$, Gowri. S 2 \\ *1, 2 Gyanodaya Vidya Mandir, India \\ DOI: https://doi.org/10.29121/granthaalayah.v8.i12.2020.2606
}

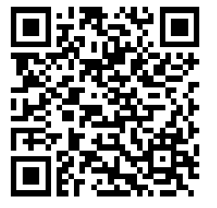

Article Type: Research Article

Article Citation: Prashant Thote, and Gowri. S. (2020). EVIDENCE

BASED LEARNING: AN ANALYSIS

OF IMPACT OF REMEDIAL

TEACHING ON CONCEPTUAL UNDERSTANDING. International Journal of Research -

GRANTHAALAYAH, 8(12), 211-224. https://doi.org/10.29121/granthaa layah.v8.i12.2020.2606

Received Date: 01 December 2020

Accepted Date: 31 December 2020

Keywords:

Small Group

Remedial Teaching

Learning Outcomes

Experiential Learning

Conceptual Understanding

\begin{abstract}
The flow in using the language of Chemistry is an important tool for students. Chemical formula is not a descriptive tool but also a heuristic tool. Most of the Secondary School students face challenges with Chemical formula (naming and writing). Inappropriate use of symbolic representation is the most common problem faced by students in Grade nine. The objective of the present paper is to enable Grade nine students to name and write the formula of Chemical compounds correctly. It is an attempt to investigate the complications faced by the students in formative assessment to acquire intended learning outcomes. To enhance the conceptual understanding and intended learning outcomes small group remedial teaching with experiential learning activities and worksheets are used. Small group work is used as a strategy to improve the learning outcomes and conceptual understanding among the students of Grade nine. The present study is limited to the students of one school and one unit of Science. Totally 40 students participate in the study. Sample students are divided into two group study group and control group equally on the basis of their previous knowledge of the subject. Students of study group are taught by using small group remedial experiential activity. The present study is experimental in nature. Data is analyzed by using mean, mean difference and standard deviation. The vital variance between the mean score of both groups on variables of pre-formative assessment and postformative assessment score is tested at 0.05 level by applying t-test. The result of the present study reveals that there is a significant positive impact of small group remedial teaching on conceptual understanding of naming and writing the Chemical formulae of Chemical compound in Science subject among the students of Grade nine. Based on the result of the study teachers must provide small group remedial teaching to the students facing challenges in conceptual understanding to acquire the intended learning outcomes.
\end{abstract}

\section{INTRODUCTION}

"The capacity to learn is gift. The ability to learn is skill. The willingness to learn is choice." - Brain Herbert.

We are living in the era of Chemicals - sugar is disaccharides, salt is Sodium Chloride, glass is super cold liquid silicates and our stomach contain $1 \mathrm{M}$ hydrochloric acid. Hence it is very important to able to recognize the chemical

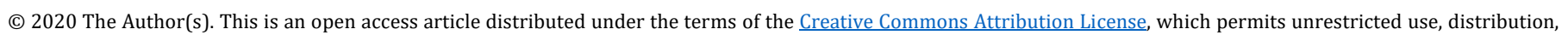
and reproduction in any medium, provided the original author and source are credited. 
compound by its name. Chemical formulas are part of chemistry's everyday language but it's like a foreign to novice students. Teachers and experts switch between many types of formulas, systematic names and common names for the chemicals. But Secondary School students face difficulties with the chemical formulas. Few students acquire fluency compared to their counterparts while other struggles which in turn hinders the students' engagement and achievement in Science subject.

Chemistry is an essential basis for everyday life and has huge unforeseen potential benefits for the future of the society. Sound understanding of the Chemistry provides individuals an opportunity to explain the life around us and take decision concerning our actions as individuals. The sound understanding of Chemistry is essential for working in almost all other Science disciplines - such as Medicine, Engineering, Environmental Science and Material Science etc. The learners, who opt for the career in these fields require sound knowledge in Chemistry and must be updated with the recent trends in Chemistry.

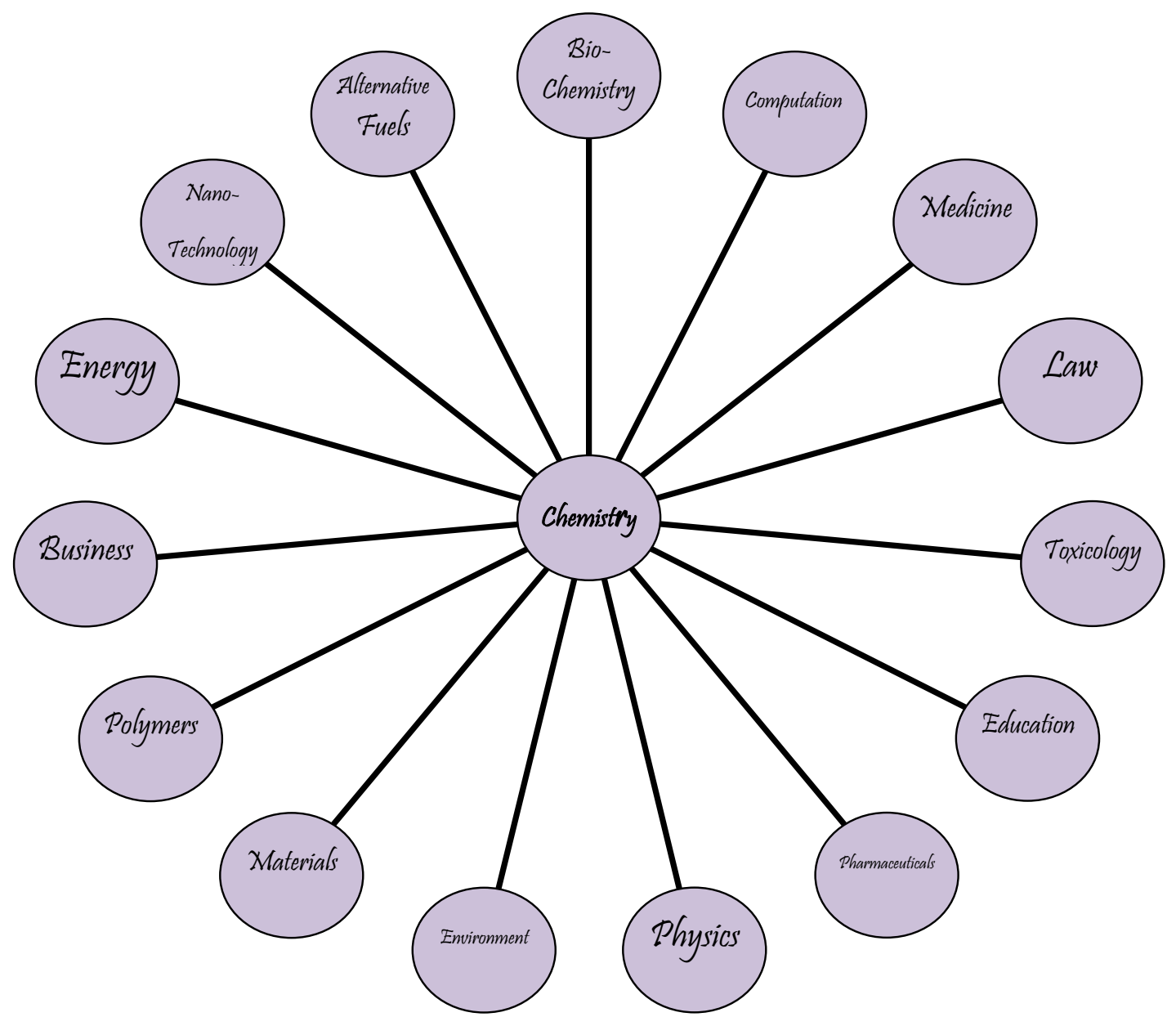

Figure 1: correlation of Chemistry with various branches.

Understanding and learning of Science concepts and principles of Chemistry is difficult. Chemistry is involved in all facets of life and yet it is cursed as much as it is praised. As a Science teacher for almost three decades my mission is to sell Chemistry as an intellectual pursuit and creative Science. It is very unlucky for a teacher that many students experience Chemistry curriculum as abstract, difficult to understand and learn and not appropriately correlated to day today life. Chemistry is widely persuaded as a difficult subject because of its specialized language, abstract nature of concept, mathematical content and amount of content to be learnt.

During the academic year 2018-19 when teaching Science in Grade nine it is observed that the majority of the students face problem in understanding, naming and writing the Chemical formula and hence the central objective 
of the present study is to enable Grade nine students to name and write the formula of inorganic compound correctly to acquire intended learning outcome of unit four "Atoms and Molecules".

The following steps are initiated to enhance students' performance, satisfaction and motivation level in classroom instructions.

\section{Step 1: Defining problem}

Students face difficulties during classroom instruction in applying the acquired concept and conceptual understanding of core concept in writing and naming the formula of inorganic compounds. After diagnosing the problem, the core objectives of the present paper are fabricated as under:

- To enable learners to name simple inorganic compound by their chemical formulae.

- To enable learners to write chemical formulae for simple inorganic compound correctly.

\section{Collection of Data}

Data is collected to enhance the conceptual understanding and application of concept - High Order Thinking Skill (HOTS) based on revised Bloom's Taxonomy in naming and writing formula of inorganic compound. Data is collected by using following tools:

- Formative Assessment - to identify the most common mistake/ error made by the learners.

- Observation - Students' participation and involvement in classroom instructions and teaching-learning process.

- Feedback - to diagnose the difficulties faced by the learners in conceptual understanding and to acquire intended learning outcomes.

\section{Step 2: Remedial Measures \\ Our strategies}

To achieve the intended learning objectives and conceptual understanding, the focus is on the following remedial strategies:

\section{First: Worksheet (Group Activity)}

Worksheet is prepared using various binary compounds. The students of the study group are divided into groups; each group consists maximum of three students and minimum of two. Each group is asked to discuss and write the name and formula of the organic compound in the blank. The present remedial strategy fosters the importance of sharing the learning among them. It fosters team building. Together everyone achieve more (TEAM).

The worksheet is fabricated in two sections (A \& B). Section A consists of compound and Section B consists of formulae of the compound.

The section A of worksheet is designed for naming the compound by applying the following rules - High Order Thinking Skills (HOTS) based on revised Bloom's Taxonomy.

1) Metal + Non-metal - Name of the compounds end with "-ite"

2) Metal + Poly atomic atom - Name of the compounds end with polyatomic ion.

3) Transition metal + Non-metal - Name of the compounds end with "-ide". The charge of the transition metal is presented in roman numerical.

4) Transition metal + Poly atomic atom -Name of the compounds end with polyatomic ion. The charge of the transition metal is presented in roman numerical.

5) Non - metal + Non-metal - Name of the compounds end with "-ide". Prefix as "mono, di, tri..." are used for all elements.

6) Binary acids - Named as hydro.... ioc acid. 
Evidence Based Learning: An Analysis of Impact of Remedial Teaching on Conceptual Understanding

Worksheet: Section A

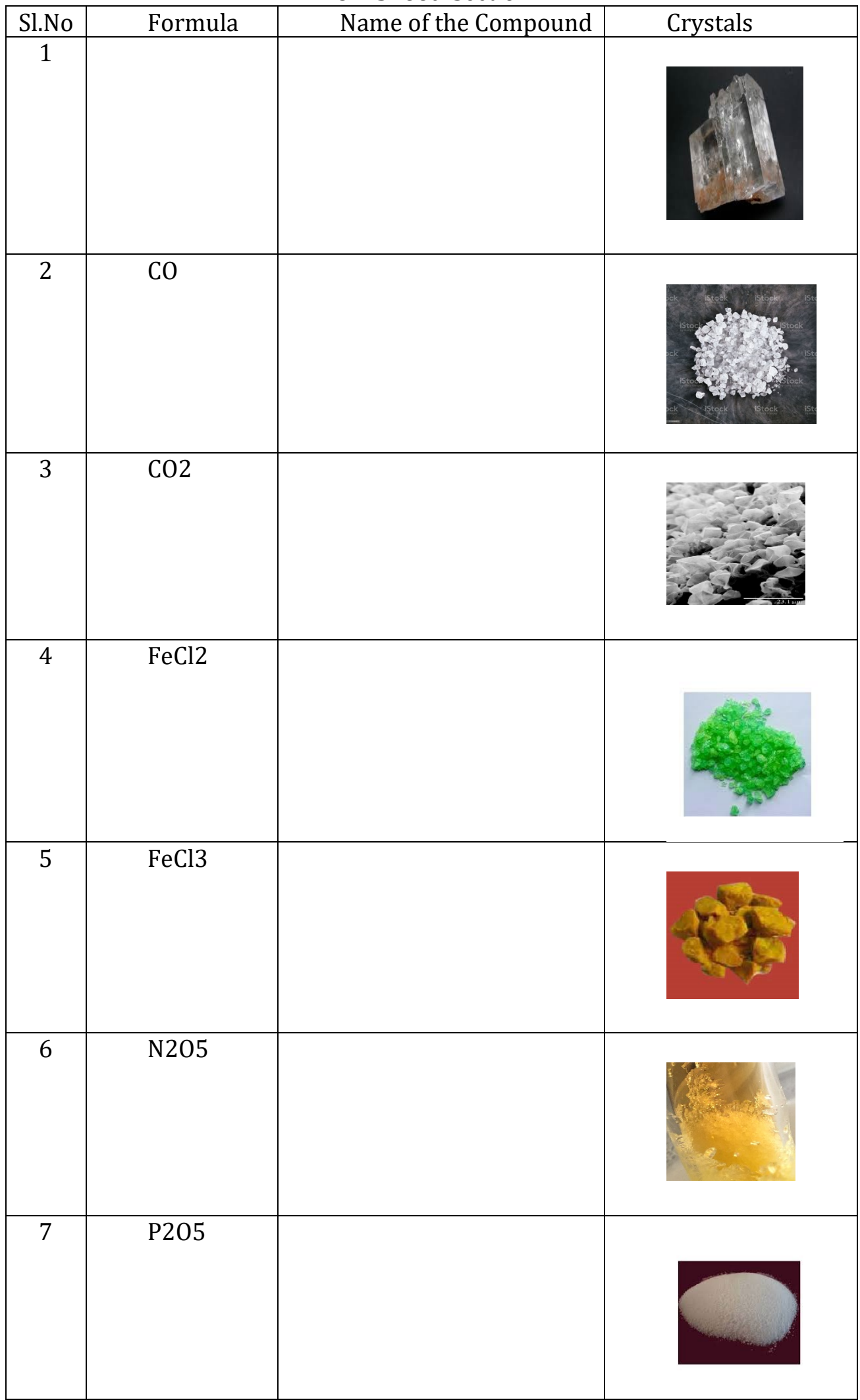


Prashant Thote, and Gowri. S

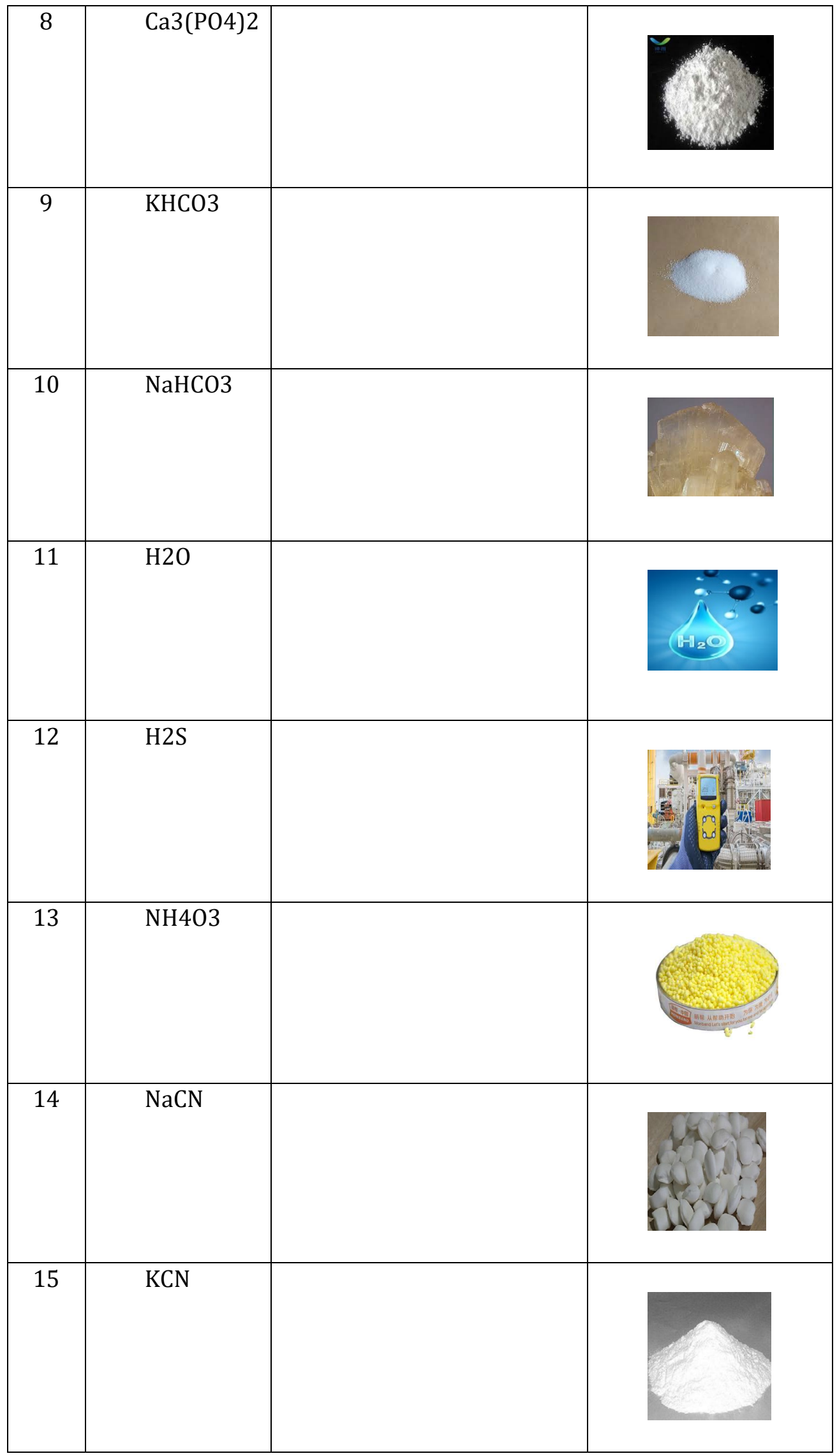


Evidence Based Learning: An Analysis of Impact of Remedial Teaching on Conceptual Understanding

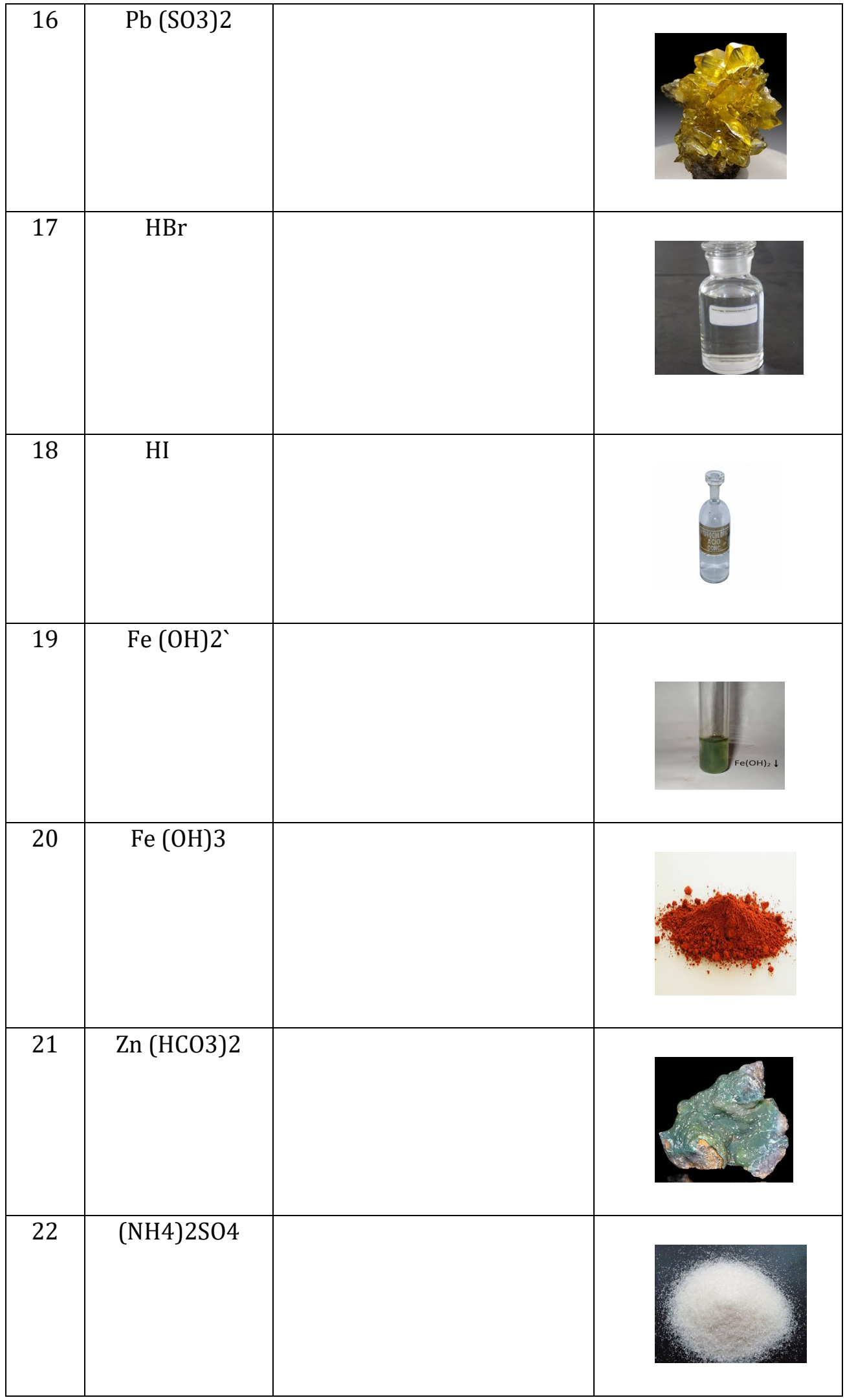


Prashant Thote, and Gowri. S

\begin{tabular}{|l|l|l|l|}
\hline 23 & $\mathrm{Al}(\mathrm{OH}) 3$ & & \\
\hline 24 & $\mathrm{CU}(\mathrm{HCO}) 2$ & & \\
\hline 25 & $\mathrm{AgI}$ & & \\
\hline & & & \\
& & & \\
& & & \\
\hline
\end{tabular}

The section B of worksheet is fabricated for writing the chemical formulae by applying the following rules - High Order Thinking Skills (HOTS) based on revised Bloom's Taxonomy.

1) Write the symbols.

2) Determine the oxidation number / charge for each of the symbol.

3) Determine the common multiple charges.

4) By applying crisscross rule to write the formulae and use 0 when containing polyatomic ions.

Worksheet: Section B

\begin{tabular}{|l|l|l|l|}
\hline Sl.No & Name of the Compound & Formula & Crystals \\
\hline 1 & Magnesium bromide & & \\
\hline 2 & Magnesium chloride & & \\
\hline 3 & Diboron tetra bromide & & \\
\hline 4 & Potassium bromide & & \\
\hline
\end{tabular}


Evidence Based Learning: An Analysis of Impact of Remedial Teaching on Conceptual Understanding

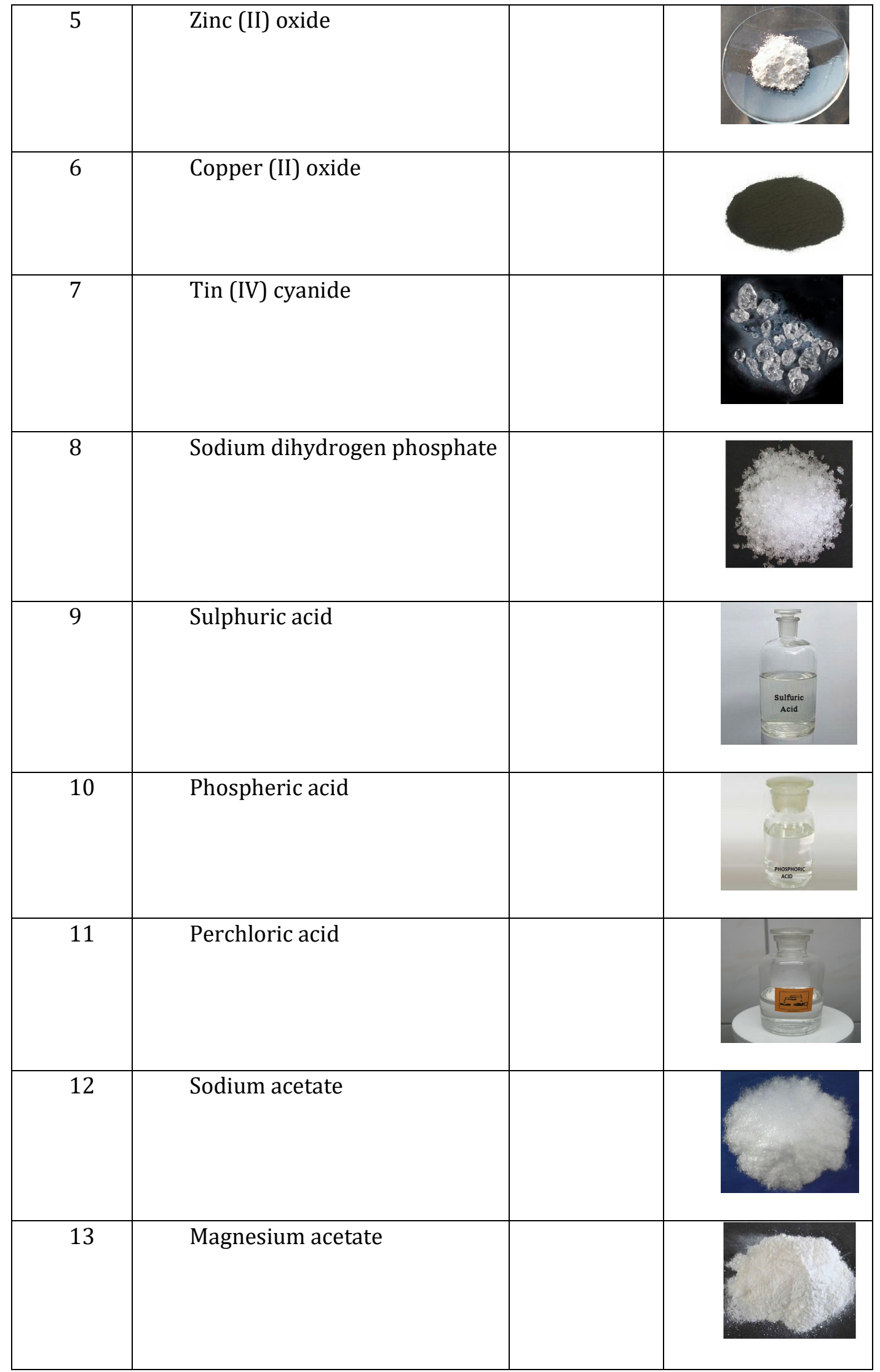


Prashant Thote, and Gowri. S

\begin{tabular}{|c|c|c|}
\hline 14 & Copper (II) bicarbonate & \\
\hline 15 & Xenon dioxide & \\
\hline 16 & Copper (I) Iodide & \\
\hline 17 & Copper (I) chloride & \\
\hline 19 & Hydrogen peroxide & \\
\hline & & \\
\hline & & \\
\hline & & \\
\hline
\end{tabular}

Strategy Two: Extended Learning Activity/Alternative Learning (Individual Activity)

Each student is asked to write the list of household products containing inorganic compounds (name and formula). This activity helps the students to achieve the intended learning outcomes and enhance conceptual understanding, deep learning and correlate the subject with day today life. It helps/ fosters the students to master the concept and interest.

Strategy Three: Extended Learning Activity/Alternative Learning (Individual Activity)

Students are asked to write the uses of household chemical compounds found in their home. This activity helps the students to identify the compounds by name and formula. This activity increases High Order Thinking Skills (HOTS) based on revised Bloom's Taxonomy. 
Evidence Based Learning: An Analysis of Impact of Remedial Teaching on Conceptual Understanding

\section{METHODS}

\subsection{DATA COLLECTION AFTER EXPERIENTIAL LEARNING}

After conducting the small group remedial experiential learning activity, data is collected on the impact of student's academic improvement and attainment of intended learning outcomes by using post-treatment formative assessment, observation and feedback.

\subsection{STATEMENT OF THE PROBLEM}

The present study is designed to explore the effect of small group remedial experiential learning activity on the academic achievement of secondary school students among Grade nine in Science subject. Hence the statement of the problem is "Evidence Based Learning: An Analysis of Impact of Remedial Teaching on Conceptual Understanding”.

\subsection{AIMS AND OBJECTIVE OF THE STUDY}

Following are the objectives of the study:

1) To explore the impact of small group remedial experiential activities on achievement of intended learning outcomes among the Grade nine students in the unit four "Atoms and Molecules".

2) To provide workable recommendation for the improvement of academic performance among Grade nine students.

\subsection{HYPOTHESIS}

Three null hypotheses are fabricated to achieve the objectives of the study.

H1: There is no noteworthy difference between the academic achievement of the study group and the control group in the formative assessment before the treatment.

H2: There is no noteworthy difference between the academic achievement of the study group and the control group in the formative assessment after the treatment.

H3: There is no noteworthy difference between the academic achievement of the study group and the control group in the summative evaluation at the retention test.

\subsection{METHODS}

Population: All students of Grade nine in the study area.

Sample: Totally 40 students of Grade nine participate in the study. Sample students are categorized into two groups (study and control group). Each group consists of twenty students.

Delimitations of the study: The present study is restricted to:

The students of only one co-educational school in the rural area.

The students of Grade nine.

Science subject.

Unit four "Atoms and Molecules".

\subsection{STUDY DESIGN}

The research study design is very important. The effectiveness of tool and study design is significant for the precision of the study. The present study is experimental in nature. The formative assessment is conducted before and after the experiment and summative evaluation at the finale of the academic year. The students are randomly distributed in the group and symbolic representations are as: 


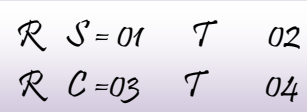

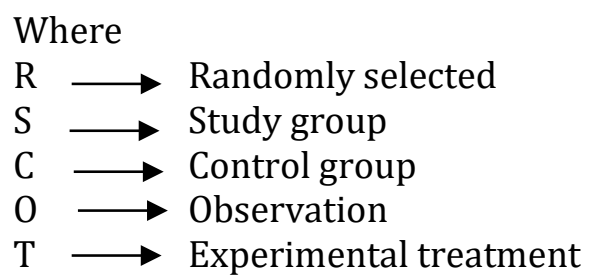

\section{Tool}

The present study is experimental in nature. Data is collected by using formative assessment (before and after the treatment) and summative evaluation as a retention test. Formative assessment and summative evaluation are fabricated by the researcher.

\section{Collection of Data}

To collect the data, formative assessment is fabricated for unit four. The raw data is obtained from test and represented in tabular form. Mean, mean difference, Standard deviation are collected for each group. Significant difference of Mean score for formative assessment before the treatment, formative assessment after the treatment and summative evaluation are tested at 0.05 level by applying t-test.

\section{RESULT AND DISCUSSIONS}

The intention of the present study is to examine the effect of small group remedial teaching experiential learning activity on the academic performance among the students of Grade nine in Science subject. The present study is experimental in nature. The formative assessment is conducted before and after the treatment for both the groups (study and control group). Students of the study group are exposed to one-week small group remedial experimental activity. The activity is conducted during the school time only. Researcher administrated the formative assessment and summative evaluation. The data is collected and compared. The entire statistical procedure is as under:

H1: There is no noteworthy difference between the academic achievement of the study group and the control group in the formative assessment before the treatment.

Table 2: Mean Score of the formative assessment of unit 4 before the experiment

N.S: $(\mathrm{P}>0.05, \mathrm{df}=38)$

\begin{tabular}{|c|c|c|c|c|c|c|}
\hline Groups & $\mathrm{N}$ & Mean & SD & SE & t-value & p-value \\
\hline Study group & 20 & 42.20 & 2.33 & 0.76 & 0.051 & 0.94 \\
\hline Control group & 20 & 42.25 & 2.43 & & & \\
\hline
\end{tabular}

table value of $t$ at $0.05=2.02$

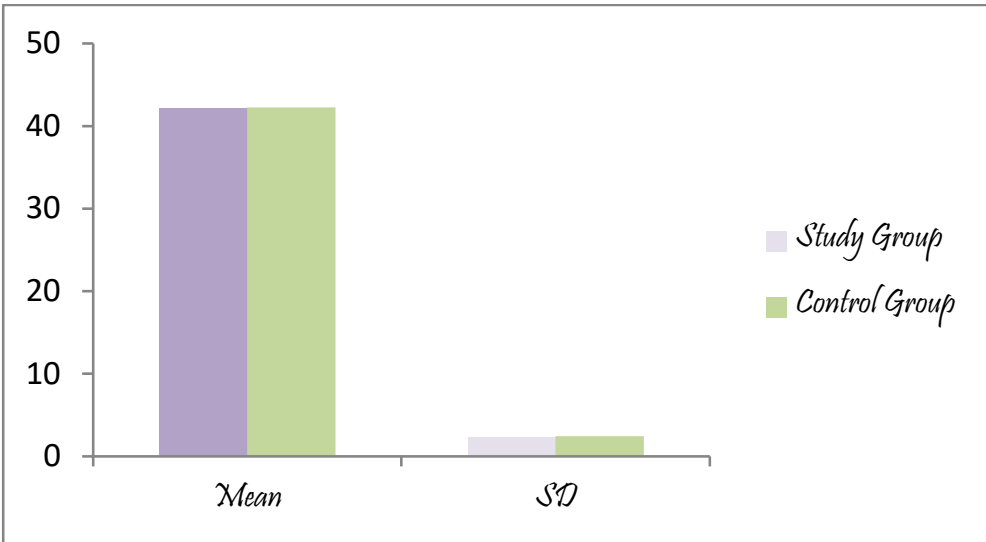

Figure 2: Mean Score of the formative assessment of unit 4 before the experiment 
Evidence Based Learning: An Analysis of Impact of Remedial Teaching on Conceptual Understanding

H2: There is no noteworthy difference between the academic achievement of the study group and the control group in the formative assessment after the treatment.

Table 3: Mean Score of the formative assessment of unit 4 after the experiment

\begin{tabular}{|l|l|l|l|l|l|l|}
\hline Groups & $\mathrm{N}$ & Mean & SD & SE & t-value & p-value \\
\hline Study group & 20 & 89.89 & 1.53 & 0.81 & 27.59 & 0.00 \\
\hline Control group & 20 & 66.35 & 3.44 & & & \\
\hline
\end{tabular}

S: $(\mathrm{P}>0.05, \mathrm{df}=38)$

table value of $t$ at $0.05=2.02$

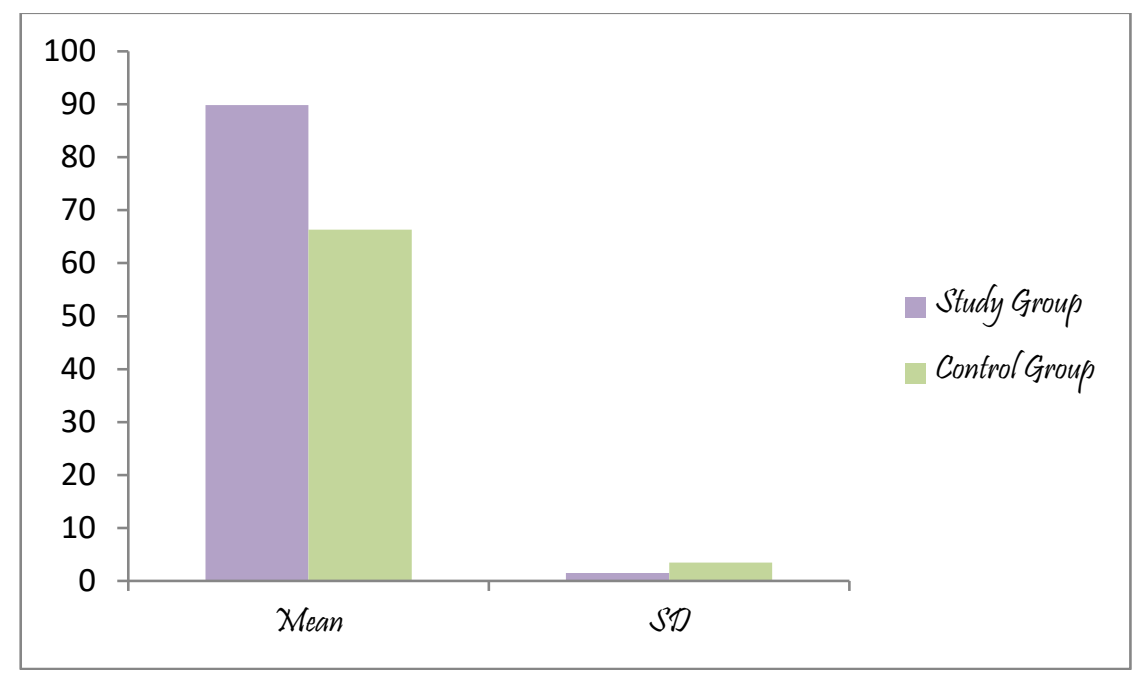

Figure 3: Mean Score of the formative assessment of unit 4 after the experiment

H3: There is no noteworthy difference between the academic achievement of the study group and the control group in the summative evaluation at the retention test.

Table 4: Mean Score of the summative evaluation

\begin{tabular}{|c|c|c|c|c|c|c|}
\hline Groups & $\mathrm{N}$ & Mean & SD & SE & t-value & p-value \\
\hline Study group & 20 & 84.89 & 2.16 & 0.62 & 32.89 & 0.00 \\
\hline Control group & 20 & 63.70 & 1.58 & & & \\
\hline
\end{tabular}

$\mathrm{S}:(\mathrm{P}>0.05, \mathrm{df}=38)$

table value of $t$ at $0.05=2.02$

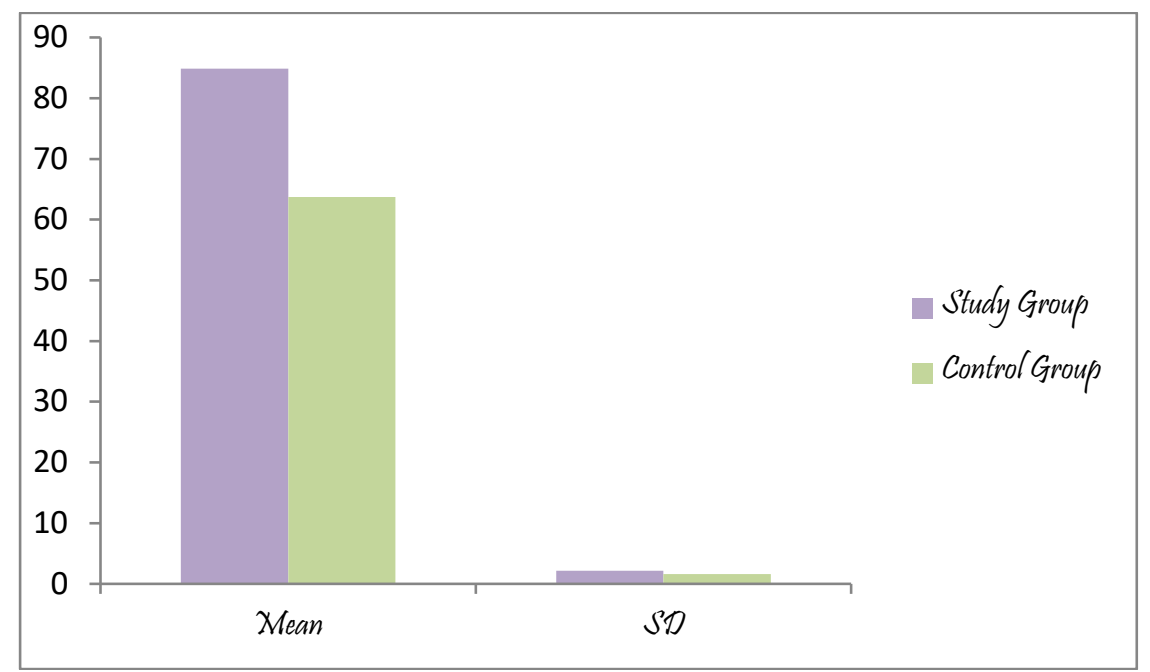

Figure 4: Mean Score of the summative evaluation 
Table 2 depicts that calculate t-value is found to be 0.051 which is statistically non-significant and it is less than critical table value at 0.05 level. Hence null hypotheses "There is no noteworthy distinction between the academic achievement of the study group and the control group in the formative assessment before the treatment" is accepted. It ambiguously reveals that learners of both groups have equally performed in the unit "Atoms and Molecules" when the unit is taught by traditional chalk and talk method.

Table 3 reveals that computed t-value (27.59) is greater than critical table value of $t$ at the level of 0.05 . Hence the null hypotheses "There is no noteworthy distinction between the academic performance of the study group and the control group in the formative assessment after the treatment" is not accepted. Result of the current study reveals that the students of the study group perform excellently well in the formative assessment conducted after the treatment as compared to the counterpart in control group. It is further clarified in Fig 3.

Result in Table 4 reveals that the computed t-value (32.89) is higher than the critical t-value at 0.05 level and hence null hypotheses "There is no noteworthy difference between the academic achievement of the study group and the control group in the summative evaluation at the retention test" is not accepted. In the summative evaluation the students of study group as enhanced than their counterparts in control group. It is further clarified in Fig 4.

\section{CONCLUSION}

The statistical analysis of the present study arrives at the following conclusion:

1) Small group remedial experiential activity in teaching-learning process has achieved admirable position in school education and acts as a potential tool to motivate the students in learning and enhances the process of deep learning. The major characteristics of small group remedial experiential learning activities are to enhance active participation of the students in teaching -learning process and acquire intended learning outcomes. The essential stimulus in developing small group teaching-learning classroom instructions are considered at class level, group composition, physical climate, existing resources, diagnostics of learning gaps and fabrication of objectives and learning outcomes.

2) The performance of students in formative assessment after the treatment and summative evaluation are significantly improved, along with deep learning, confidence, self-esteem, competence, positive attitude towards self-learning.

3) Small group remedial experiential activities have significant impact on academic achievement of study group and hence it is highly useful due to its fulfillment of individual learning gaps.

\section{Concluding remarks}

In nutshell it is concluded that small group remedial experiential learning activities have significant positive impact on academic performance among the students of Grade nine in Science.

\section{RECOMMENDATIONS}

On the basis of the conclusion of the research following recommendation is made.

- Small group remedial experiential learning activity has gained an admirable position in school education and well linked with stimulating learners and enhancing the conceptual understanding. Effective learning takes place in groups. Small group activity in experiential leaning enhances the process of conceptual understanding, deep learning and its application. Student's retention of knowledge enhances the transformation of concept to novel issues, critical skills, team work abilities, self-directed learning, communication skills, student-student and student-teacher interactions. Hence researcher strongly recommends the remedial measure of small group experiential learning activities.

\section{SOURCES OF FUNDING}

This research received no specific grant from any funding agency in the public, commercial, or not-for-profit sectors. 
Evidence Based Learning: An Analysis of Impact of Remedial Teaching on Conceptual Understanding

\section{CONFLICT OF INTEREST}

The author have declared that no competing interests exist.

\section{ACKNOWLEDGMENT}

None.

\section{REFERENCES}

[1] Prashant Thote, Experiential Learning: Inclusive Art Education for Joyful Learning, Review of Research, Vol 8, Issue- 09, June 2019.

[2] Prashant Thote, Experiential Learning: Model for Teaching Science at Grade Nine, Research Magma, Vol-3, Issue -06, August - 2019.

[3] Prashant Thote, An Analysis of Impact of Evidence Based Learning on Academic Achievement of Students, International Journal of Research- Granthaalayah, Vol 8, Issue- 08, August 2020.

[4] Prashant Thote, Experiential Learning: An Analysis of Impact on Academic Achievement Among Students of Grade 12, International Journal of Research- Granthaalayah, Vol 8, Issue- 09, September 2020.

[5] Prashant Thote, Evidence Based Learning: An Analysis of Impact on Retention of Knowledge, International Journal of Research- Granthaalayah, Vol 8, Issue- 10, October 2020.

[6] Prashant Thote, Outcome Based Learning: An Analysis of Impact on Academic Achievement Among School Students, International Journal of Research- Granthaalayah, Vol 8, Issue- 11, November 2020. 